\title{
As Escalas Geográficas da Certificação ISO 14001: um panorama da gestão ambiental empresarial
}

\section{Geographic Scales of Certification ISO 14001: an Overview of Corporate Environmental Management}

\author{
Henrique Elias Pessoa GUTIERRES*
}

\begin{abstract}
RESUMO
A certificação ambiental, em especial a norma ISO 14001, demonstra a existência de fatores internos e externos para a melhoria do desempenho ambiental das empresas. Assim, este artigo tem como objetivo apresentar um panorama atual da certificação ISO $14001 \mathrm{em}$ diferentes escalas de análise (mundial, nacional, regional e estadual), buscando a sua territorialização, considerando fatores de localização, extensão e conexão. Adotou-se como procedimentos: o levantamento do referencial teórico; a aquisição de dados junto à ISO (International Organization for Standardization) e ao INMETRO (Instituto Nacional de Metrologia, Normalização e Qualidade Industrial) do quantitativo de empresas certificadas pela ISO 14001. Após a organização dos dados, houve a sistematização por meio de tabelas através de planilha eletrônica, finalização da apresentação em gráficos e análise dos dados relacionando-os ao Índice de Desenvolvimento Humano (IDH) e ao Produto Interno Bruto (PIB). Entende-se que a maior parte desses certificados está concentrada nos países desenvolvidos, sede das matrizes das grandes empresas. Na realidade brasileira, a relação (número de certificações, PIB e IDH por unidade da federação) não se mostrou tão evidente, tendo sido constatados Estados com PIB e IDH inferiores, mas com maior quantidade de certificados em relação a alguns Estados mais bem posicionados socioeconomicamente. Esta característica tem a ver com aspectos econômicos das empresas que exercem forte influência na ocorrência desses certificados. Logo, apresenta-se uma realidade espacialmente desigual, em que nem sempre a certificação ambiental tem relação com a realidade local, sendo uma exigência de fatores externos, como a continuidade em se relacionar com clientes e fornecedores que detêm a certificação ambiental, portanto, algo de fora para dentro, agindo na realidade local.
\end{abstract}

Palavras-chave: certificação ambiental; diferentes escalas; realidade local.

\begin{abstract}
Environmental certification, especially ISO 14001, demonstrates the existence of internal and external factors for improving the environmental performance of companies. Thus, this article aims to present
\end{abstract}

\footnotetext{
"Mestre em Geografia (UFPB). Geógrafo da Universidade Federal da Paraíba (UFPB). E-mail: hepg86@hotmail.com
} 
a current overview of ISO 14001 certification at different scales of analysis (global, national, regional and state), seeking its territoriality by considering factors of location, extent and connection. The following procedures were adopted: a survey of the theoretical reference, the acquisition of data from the ISO (International Organization for Standardization) and INMETRO (National Institute of Metrology, Standardization and Industrial Quality) on the quantity of companies certified by ISO 14001. After organizing the data, there was systematization through tables via spreadsheet, presentation and finalization of graphs and data analysis relating to the Human Development Index (HDI) and Gross Domestic Product (GDP). It is understood that most of these certificates is concentrated in developed countries, where the headquarters of large companies are located. Considering the Brazilian reality, the ratio (number of certifications, GDP and HDI by state) was not so obvious, since there are states with lower GDP and HDI, but with higher certificates compared to some states that are better positioned socio-economically. This feature has to do with economic aspects of the companies that have a strong influence on the occurrence of these certificates. Therefore, we present a spatially uneven reality where the environmental certification is not always related to the local reality, being a requirement of external factors, such as a continuing relation with customers and suppliers who hold environmental certification. Therefore, it is something external acting in local reality.

Keywords: environmental certification; different scales; local reality.

\section{Introdução}

A disseminação da preocupação ambiental em diferentes setores da sociedade é uma realidade neste início de século. O setor empresarial não foge à regra e passou a incorporar a gestão ambiental às suas atividades, resultante do aprimoramento da legislação ambiental e fiscalização dos órgãos públicos, além da sobrevivência perante o mercado internacional globalizado. Parte das empresas instaladas no Brasil tem dado uma maior atenção ao seu desempenho ambiental, pois algumas são filiais de transnacionais e seguem as diretrizes vindas do exterior para que adotem padrões corporativos, sobretudo com interesse em preservar a imagem e resguardá-la de problemas.

A certificação ambiental, com a implantação do respectivo Sistema de Gestão Ambiental (SGA), em especial aquele estabelecido pela Norma ISO 14001, demonstra a existência de fatores internos e externos ao ambiente empresarial no interesse por tal instrumento. A sua presença gera uma tendência na melhoria das práticas ambientais do setor empresarial (privado, público ou misto), bem como numa relação de maior proximidade com as partes interessadas externas. Contudo, essa realidade é espacialmente desigual, pois nota-se uma territorialização da certificação ISO 14001. Ou seja, o entendimento da distribuição geográfica das empresas certificadas pela citada norma, juntamente com o levantamento das causas dessa distribuição e as possíveis interferências e repercussões no espaço geográfico resultante desse instrumento de planejamento e gestão ambiental, permite traçar um panorama geográfico atual em diferentes escalas (mundial, nacional, regional e estadual). Assim, é possível considerar que os fenômenos socioambientais se articulam entre si nos diferentes níveis e escalas, porém apresentam efeitos que não são igualmente sentidos nos diferentes níveis e escalas.

\section{Gestão ambiental nas empresas}

A gestão ambiental empresarial, para Viterbo Jr. (1998, p. 51), "nada mais é do que a forma como uma organização administra as relações entre suas atividades e o meio ambiente que as abriga, observadas as expectativas das partes interessadas", enquanto que Teodoro (2002, p. 35) a entende "como o conjunto de práticas definidas e sistematizadas aplicadas por um determinado empreendimento com a finalidade de reduzir e controlar impactos ambientais".

A presença da preocupação ambiental perpassa pelo atual processo de globalização financeira e de produção na economia em todo mundo. Essa realidade está presente naquelas empresas mais competitivas in- 
ternacionalmente, forçando uma postura mais proativa da mesma. Callenbach et al.(1993) consideram que essa mudança está diretamente associada à relação entre paradigma social e cultura empresarial. Porém, esses dois conceitos norteadores tiveram e continuam apresentando diferenças e modificações de acordo com a localização geográfica da organização, como também temporalmente. Partindo desse entendimento, Donaire (1995) demonstra a existência da organização sob duas óticas diferentes: tradicional e moderna. Na visão tradicional, a organização é tida como uma instituição econômica com o objetivo principal de adquirir e maximizar seus lucros. Na visão moderna, os aspectos sociais e políticos são considerados e o aspecto ambiental torna-se um critério de ganho e melhoria de imagem perante a sociedade. Essa evolução das visões para Donaire (1995) constitui um reflexo do próprio sistema capitalista, que apesar do "sucesso" econômico e monetário, não conseguiu eliminar ou minimizar problemas sociais graves (pobreza, poluição, qualidade de vida nas cidades, etc.). Essa visão vem sendo incorporada por algumas empresas, que crescentemente notam a necessidade de envolver os atores externos ao seu ambiente.

Dessa forma, Dias (2011) enfatiza que a nova postura empresarial quanto à questão ambiental é fruto também da atuação coercitiva de grupos sociais externos à organização (clientes, acionistas, Organizações Não Governamentais - ONGs, partidos políticos, grupos organizados de consumidores, comunidades vizinhas, mídia, etc.), obrigando a empresa a entender que, caso deseje desenvolver e alcançar o consenso ambiental internamente, necessita acompanhar as mudanças de conduta e de pensamento por toda força de trabalho, não podendo se impor tal consenso de cima para baixo, embora a sanção da alta administração seja fundamental para as mudanças (CALLENBACH, 1993).

Por isso, a maior relevância que se tem dado atualmente à perspectiva de integrar as análises ambiental e econômica fez com que normas mais complexas referentes à gestão ambiental viessem a ser criadas. Se antes as normas ambientais aplicadas às empresas estavam restritas ao acompanhamento por parte dos órgãos ambientais no momento do licenciamento de seu projeto, de instalação e depois de operação, agora se constituem em meios para aperfeiçoar a relação positiva da empresa com o meio ambiente (GUTIERRES, 2011).

\section{Sistema de Gestão Ambiental: Norma ISO 14001}

A série ISO 14000 é composta por um conjunto de normas, destacando-se a ISO 14001 (Sistemas de Gestão Ambiental - Especificações com Guia para Uso), que foi a primeira a ser lançada, em 1996, estabelecendo as especificações e os critérios de como se implementar um SGA. A ABNT (2004) define o SGA como a parte de um sistema da gestão de uma organização utilizada para desenvolver e implementar sua política ambiental e para gerenciar seus aspectos ambientais.

Com a disseminação da concessão de certificados pelo mundo, a ISO realizou a primeira revisão da norma em 2004 (ISO 14001:2004), sendo que, depois de um período de dezoito meses para adequação, as organizações que já eram certificadas ou estavam prestes a ser passaram a obedecer a esta nova versão, a partir do mês de maio de 2006. Contudo, a ISO 14001 esclarece que a elaboração das normas não teve a finalidade de criar barreiras comerciais "não tarifárias", nem de alterar ou aumentar as obrigações da empresa, e sim modificar modos de produção na busca por um modelo econômico sustentável, pretendendo aplicá-las a todos os tipos e portes de organizações, além de adequá-las às diferentes condições geográficas, culturais e sociais (ABNT, 2004). Viterbo Júnior (1998) reforça tal entendimento afirmando que o texto da ISO 14001 prima pela subjetividade, pois serve para qualquer tipo de organização.

De acordo com o texto da ABNT NBR ISO 14001:2004, a ISO 14001 é baseada na metodologia Plan-Do-Check-Act (PDCA): Planejar-Executar-Verificar-Agir, estabelecendo um sistema de gestão formado por cinco elementos estruturais que se sucedem e mantêm relação entre si, objetivando estabelecer, implementar, manter e continuamente melhorar o SGA na organização: Política Ambiental; Planejamento; Implementação e Operação; Verificação e Ação Corretiva e Análise Crítica pela Administração (Figura 1). 


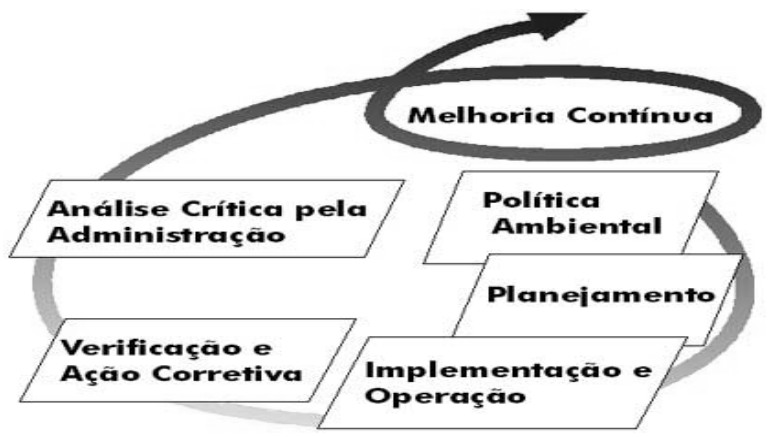

FIGURA 1 - Modelo de Sistema da Gestão Ambiental para Norma ISO 14001.

\section{Metodologia}

Os procedimentos operacionais adotados tiveram como referência o trabalho de Gutierres (2008) e uma atualização dos dados no ano de 2013, baseados na abordagem geográfica para estudos de gestão do meio ambiente, tomando Xavier da Silva (1995) como referência, no tocante à compreensão dos dados analisados através dos aspectos de localização, extensão, contiguidade e conexão do tema pesquisado.

A etapa da aquisição de dados consistiu em pesquisas nos sites da ISO (International Organization for Standardization) e do INMETRO (Instituto Nacional de Metrologia, Qualidade e Tecnologia), objetivando obter os dados primários sobre o quantitativo de empresas certificadas pela norma ISO 14001:2004 em diferentes escalas de análise (mundial, nacional, regional e estadual). Num segundo momento, objetivando estabelecer relações geográficas entre o número de organizações certificadas pela norma ISO 14001 e as condições socioeconômicas, foram utilizados os dados mais recentes referentes ao Índice de Desenvolvimento Humano (IDH) e do Produto Interno Bruto (PIB) dos Estados brasileiros, tendo como fonte o Instituto Brasileiro de Geografia e Estatística (IBGE).

Após a obtenção dos dados anteriormente citados, houve a sistematização e a organização dos mesmos por meio de tabelas elaboradas em planilha eletrônica e finalização com a organização dos dados por meio de gráficos.

\section{Geografia da Certificação ISO 14001}

\section{Escala Mundial}

Para construção do panorama mundial das certificações ISO 14001, foram utilizados os dados da ISO dos anos de 1999, 2005 e 2011. Assim, o panorama mundial procurou demonstrar a distribuição quantitativa das certificações da norma 14001:2004 entre os continentes (Europa, Ásia, África, Oceania e América).

A análise dos dados (Quadro 1) demonstra a concentração dos certificados ISO 14001 na Ásia, Europa e América do Norte, onde se encontram os países de maior PIB e IDH. Observa-se que, em 1999, 97\% dos

QUADRO 1 - DADOS COMPARATIVOS DA CERTIFICAÇÃO ISO 14001 NO MUNDO NOS ANOS DE 2005 E 2006

\begin{tabular}{|c|c|c|c|c|c|c|}
\hline Continentes & $\begin{array}{c}\text { Valor Absoluto } \\
\mathbf{( 1 9 9 9 )}\end{array}$ & $\begin{array}{c}\text { Participação } \\
\text { Mundial (1999) }\end{array}$ & $\begin{array}{c}\text { Valor Absoluto } \\
\mathbf{( 2 0 0 5 )}\end{array}$ & $\begin{array}{c}\text { Valor Relativo } \\
\text { Participação } \\
\text { Mundial (2005) }\end{array}$ & $\begin{array}{c}\text { Valor Absoluto } \\
\text { (2011) }\end{array}$ & $\begin{array}{c}\text { Valor Relativo } \\
\text { Participação } \\
\text { Mundial (2011) }\end{array}$ \\
\hline África & $\mathbf{1 2 9}$ & $\mathbf{0 , 9 \%}$ & 1.130 & $1,0 \%$ & 1.740 & $0,7 \%$ \\
\hline $\begin{array}{c}\text { Américas do Sul e } \\
\text { Central }\end{array}$ & $\mathbf{3 0 9}$ & $\mathbf{2 , 2 \%}$ & 3.411 & $3,1 \%$ & 7.067 \\
\hline América do Norte & $\mathbf{9 7 5}$ & $\mathbf{7 \%}$ & 7.119 & $6,4 \%$ & 7.465 & $2,6 \%$ \\
\hline Europa & $\mathbf{7 . 2 5 3}$ & $\mathbf{5 2 \%}$ & 47.837 & $43,0 \%$ & 106.700 & $40,0 \%$ \\
\hline Ásia/ Oceania & $\mathbf{5 . 3 2 8}$ & $\mathbf{3 8 \%}$ & 51.666 & $46,5 \%$ & 144.485 & $54,0 \%$ \\
\hline Total & $\mathbf{1 3 . 9 9 4}$ & $\mathbf{1 0 0 \%}$ & $\mathbf{1 1 1 . 1 6 3}$ & $\mathbf{1 0 0 , 0} \%$ & $\mathbf{2 6 7 . 4 5 7}$ & $\mathbf{1 0 0 , 0 0 \%}$ \\
\hline
\end{tabular}

Org.: Do Autor.

FONTE: ISO. 
certificados ISO 14001 estavam nesse continente, caindo para $95,9 \%$ em 2005 e subindo para $96,9 \%$ em 2011, enquanto os continentes predominantemente subdesenvolvidos (África e América Central e do Sul) respondem por uma pequena parcela do total mundial, apresentando um crescimento de 1999 para 2005, porém diminuindo de 2005 para 2011. Quanto ao total mundial, o aumento de 1999 para 2005 foi de quase oito vezes (quase 100 mil novos certificados), enquanto de 2005 para 2011 houve o dobro desse total.

Isso possivelmente pode comprovar a tendência de os certificados ambientais continuarem a ter os países desenvolvidos como principais "consumidores" dessa norma. Comparando o valor relativo de participação por cada continente nos anos analisados, apenas a Ásia/ Oceania manteve um aumento contínuo na participação mundial, que em 1999 era de 38\% e em 2011 alcançou $54 \%$ dos certificados ISO 14001 em todo mundo.

\section{Escala nacional}

A análise da distribuição dos certificados ISO 14001 no Brasil foi realizada a partir dos dados disponibilizados pelo INMETRO (Instituto Nacional de Metrologia, Normalização e Qualidade Industrial), que congrega os certificados concedidos pelos organismos credenciados junto ao Sistema Brasileiro de Avaliação da Conformidade (SBAC). A Base de Dados de Empresas Certificadas com ISO 14001 do INMETRO foi consultada em abril de 2008 e em abril de 2013, registrando um total de 744 unidades de negócio certificadas em 2008 e 207 unidades em 2013. A escala regional considerou as cinco grandes regiões brasileiras definidas pelo IBGE: Norte, Nordeste, Centro-Oeste, Sudeste e Sul, que apresentam diferenças internas e entre si de ordem natural, cultural, política, social e econômica. As diferenças socioeconômicas foram tomadas como referência para o estudo da geografia das certificações ISO 14001, relacionando as certificações aos dados do PIB (Produto Interno Bruto) e ao IDH (Índice de Desenvolvimento Humano) de cada unidade da federação (Quadro 2).
QUADRO 2 - PIB E IDH POR UNIDADES DA FEDERAÇÃO

\begin{tabular}{|c|c|c|c|c|}
\hline $\begin{array}{c}\text { Unidade } \\
\text { Federativa } \\
\end{array}$ & $\begin{array}{c}\text { PIB (milhões } \\
\text { de reais) }\end{array}$ & $\begin{array}{c}\text { Posição } \\
\text { (PIB) }\end{array}$ & IDH & $\begin{array}{c}\text { Posição } \\
\text { (IDH) }\end{array}$ \\
\hline SP & 1.247 .596 & $1^{\mathrm{o}}$ & 0,82 & $3^{\circ}$ \\
\hline $\mathrm{RJ}$ & 407.123 & $2^{\circ}$ & $\mathbf{0 , 8 0 7}$ & $5^{\circ}$ \\
\hline MG & 351.381 & $3^{\circ}$ & 0,773 & $9^{\circ}$ \\
\hline $\mathrm{RS}$ & 252.483 & $4^{\circ}$ & 0,814 & $4^{\circ}$ \\
\hline PR & 217.290 & $5^{\circ}$ & 0,787 & $6^{\circ}$ \\
\hline $\mathrm{BA}$ & 154.340 & $6^{\circ}$ & 0,688 & $22^{\circ}$ \\
\hline $\mathrm{SC}$ & 152.482 & $7^{\circ}$ & 0,822 & $2^{\circ}$ \\
\hline DF & 149.906 & $8^{\circ}$ & 0,844 & $1^{\circ}$ \\
\hline GO & 97.576 & $9^{\circ}$ & 0,776 & $8^{\circ}$ \\
\hline $\mathrm{PE}$ & 95.187 & $10^{\circ}$ & 0,705 & $18^{\circ}$ \\
\hline ES & 82.122 & $11^{\circ}$ & 0,765 & $11^{\circ}$ \\
\hline $\mathrm{CE}$ & 77.865 & $12^{\circ}$ & 0,7 & $20^{\circ}$ \\
\hline $\mathrm{PA}$ & 77.848 & $13^{\circ}$ & 0,723 & $15^{\circ}$ \\
\hline $\mathrm{AM}$ & 59.779 & $14^{\circ}$ & 0,713 & $16^{\circ}$ \\
\hline MT & 59.600 & $15^{\circ}$ & 0,773 & $9^{\circ}$ \\
\hline MA & 45.256 & $16^{\circ}$ & 0,636 & $27^{\circ}$ \\
\hline MS & 43.514 & $17^{\circ}$ & 0,778 & $7^{\circ}$ \\
\hline $\mathrm{RN}$ & 32.339 & $18^{\circ}$ & 0,705 & $18^{\circ}$ \\
\hline $\mathrm{PB}$ & 31.947 & $19^{\circ}$ & 0,661 & $24^{\circ}$ \\
\hline $\mathrm{AL}$ & 24.575 & $20^{\circ}$ & 0,649 & $26^{\circ}$ \\
\hline SE & 23.932 & $21^{\circ}$ & 0,682 & $23^{\circ}$ \\
\hline RO & 23.561 & $22^{\circ}$ & 0,735 & $14^{\circ}$ \\
\hline PI & 22.060 & $23^{\circ}$ & 0,656 & $25^{\circ}$ \\
\hline TO & 17.240 & $24^{\circ}$ & 0,71 & $17^{\circ}$ \\
\hline $\mathrm{AC}$ & 8.477 & $25^{\circ}$ & 0,697 & $21^{\circ}$ \\
\hline AP & 8.266 & $26^{\circ}$ & 0,753 & $12^{\circ}$ \\
\hline RR & 6.341 & $27^{\circ}$ & 0,746 & $13^{\circ}$ \\
\hline
\end{tabular}

Org: Do Autor.

FONTE: IBGE (PIB - 2010 e IDH - 2007).

Inicialmente, o gráfico da distribuição regional evidencia a superioridade da região Sudeste nos dois anos considerados, totalizando 479 unidades de negócio em 2008 (65\% dos certificados) e 207 unidades de negócio em 2013 (51,7\% dos certificados) (Figura 2).

Em 2008, a região Sul contabilizou 125 unidades de negócio certificadas e 65 unidades em 2013, representando aproximadamente $17 \%$ e $31 \%$ do total, respectivamente, sendo a região que apresenta o menor desequilíbrio no número de certificados entre seus Estados. O Nordeste posiciona-se em terceiro, totalizando 80 unidades (quase $11 \%$ de participação nacional) no ano de 2008, das quais 66 estão presentes nos Estados de maior PIB da região (Bahia, Pernambuco e Ceará), 


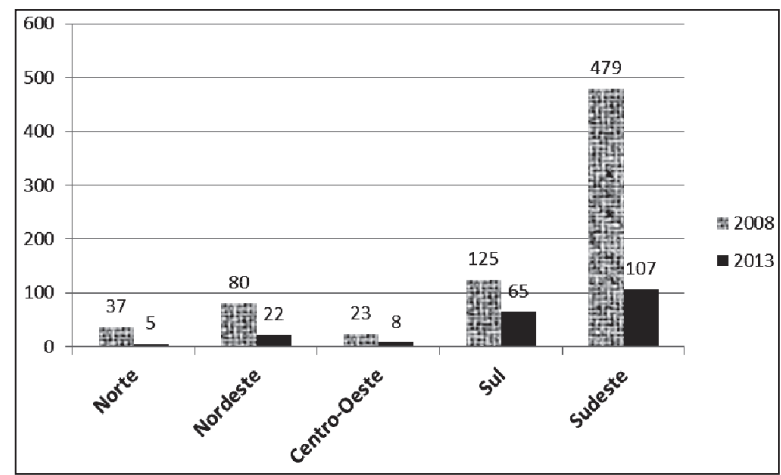

FIGURA 2 - Quantidade de Certificados ISO 14001 por regiões brasileiras nos anos de 2008 e 2013.

Org.: Do Autor.

FONTE: INMETRO.

caracterizando uma distribuição desigual entre as suas unidades federativas. Em 2013, o INMETRO registra 22 unidades de negócio, o que equivale a aproximadamente $10 \%$ na participação nacional.

A região Norte é a maior em extensão, no entanto, grande parte dessa área está ocupada por áreas protegidas (unidades de conservação, reserva legal, florestas em geral); além disso, apresenta baixa ocupação populacional (abriga $10 \%$ da população do país). Inicialmente esse cenário poderia ser suficiente para afirmar que essa região seria a última no número de certificados entre as regiões. A constatação poderia ainda ser reforçada pelo fato de a maioria dos seus Estados (Roraima, Rondônia, Acre, Amapá e Tocantins) possuírem PIB inferior aos da região Centro-Oeste (região de menor número de certificações). Porém, segundo os dados de 2008, a região Centro-Oeste é a que apresenta o menor número (apenas vinte e três unidades), representando uma participação de apenas 3,1\% no total nacional.

Percebe-se que, em termos socioeconômicos, a região Centro-Oeste tem suas quatro unidades federativas na lista do IDH e duas entre as dez mais ricas do país, porém, apresenta o menor número de certificações no ano de 2008, tendo mudado de cenário em 2013, quando ultrapassou a região Norte. Em princípio, poderia ser levantada a hipótese da baixa ou inexistente relação desses dois indicadores com a presença da certificação ambiental. No outro extremo encontra-se a região Norte, pois nota-se não ter nenhum Estado de destaque no IDH e PIB, contudo, apresenta 37 unidades certificadas em 2008, quase o dobro da região Centro-Oeste.

\section{Região Norte}

A região Norte mostra-se desigual, pois, dos sete Estados, apenas três possuíam alguma empresa certificada pela norma ISO 14001:2004 em 2008 e apenas o Estado do Amazonas no ano de 2013.

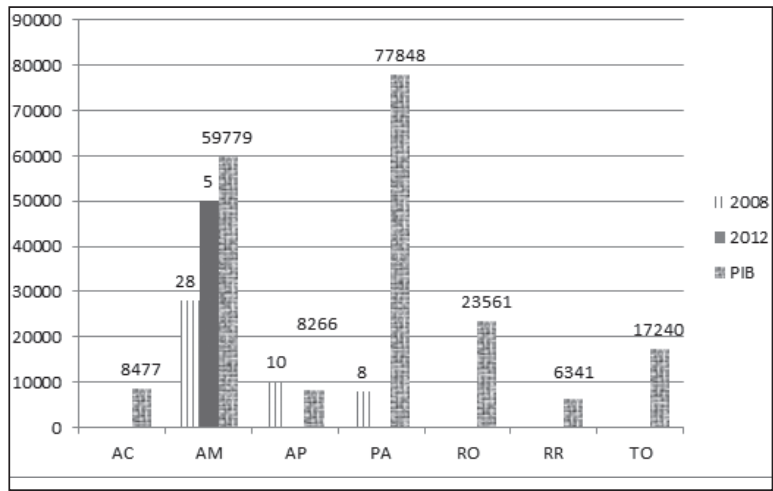

FIGURA 3 - Quantidade de certificados ISO 14001 e valor do PIB (em milhões de reais) na região Norte nos anos de 2008 e 2013. Fonte dos dados: INMETRO.

Org.: Autor.

As certificações da região representam aproximadamente 5\% do total nacional. Em 2008, o Amapá possuía apenas uma unidade de negócio da Eletronorte (Centrais Elétricas do Norte do Brasil S/A). As demais certificações estão nos Estados mais ricos da região (Pará e Amazonas). Economicamente, o Pará é lembrado pelas províncias minerais, especialmente a Serra de Carajás. A mineração constitui importante receita da economia estadual, não sendo surpresa constatar que as oito unidades de negócio certificadas estão diretamente relacionadas à atividade de mineração. $\mathrm{O}$ Estado tem o décimo terceiro maior PIB do país em 2010, mesmo assim suas certificações representavam apenas $1,1 \%$ do total nacional em 2008.

Em 2008, o Estado do Amazonas possuía 28 unidades certificadas, o que representa aproximadamente $75 \%$ dos certificados na região. Mesmo apresentando PIB e IDH piores do que os do Estado do Pará, detém quase 
quatro vezes mais certificações. Observando a relação das empresas, percebe-se que há uma diferença quanto à localização geográfica dessas unidades em relação às do Pará. Ocorre um predomínio de empresas instaladas na capital do Estado (Manaus), diferente do Pará, que, com exceção de apenas uma unidade, tem as demais localizadas no interior do Estado. Chega-se à constatação que a concentração das certificações na capital do Estado está diretamente relacionada à Zona Franca de Manaus. Foi criada em 1957 e o Governo Federal estabeleceu incentivos fiscais por 30 anos para a implantação de um polo agropecuário, comercial e industrial.

\section{Região Nordeste}

A desigualdade na distribuição das certificações na região Nordeste expressa as diferenças econômicas entre suas unidades federativas. Verifica-se que os três Estados de maior PIB (Bahia, Pernambuco e Ceará) também são os que apresentam maior número de empresas certificadas (Figura 4).

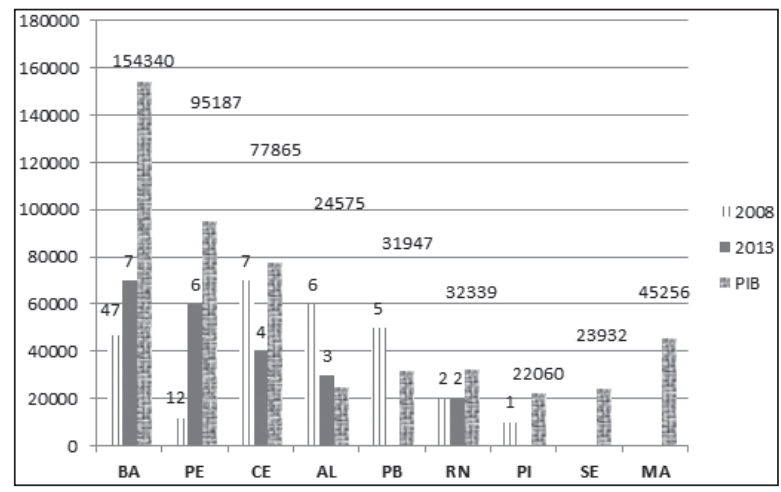

FIGURA 4 - Quantidade de certificados ISO 14001 e valor do PIB (em milhões de reais) na região Nordeste nos anos de 2008 e 2013. FONTE: INMETRO.

Org.: Do Autor.

No ano de 2008, o Estado da Bahia apresentava um total de 47 unidades de negócio, ou seja, 58,75\% das certificações na região. Como Estado mais rico do Nordeste (36\% da riqueza regional), possui o Polo de Camaçari como área econômica de destaque, abrigando empresas de diversos setores (químico, petroquímico, indústria automotiva, de celulose, metalurgia do cobre, têxtil, bebidas e serviços). Por isso, constata-se que as empresas certificadas com ISO 14001 na Bahia, em sua maioria, são as que estão instaladas em Camaçari ou em municípios vizinhos, havendo uma predominância das multinacionais com produção voltada para o mercado externo. Neste universo, o destaque é para a empresa Braskem S.A., do setor petroquímico, que totaliza sete unidades de negócio certificadas. Em 2013, o INMETRO indica a existência de sete unidades de negócios certificadas no Estado.

Pernambuco surge como o segundo maior detentor regional, com doze unidades de negócio ( $15 \%$ das certificações do Nordeste) no ano de 2008. Esse quantitativo é representado por uma diversidade de setores (engenharia, indústrias de transformação de borracha, química, produtos metálicos, geração de energia, hotelaria, etc.). Enquanto localização dessas empresas, os destaques são para o Complexo Industrial Portuário de Suape e o arquipélago de Fernando de Noronha, embora não se tenha constatado certificados nas empresas instaladas no Polo de Fruticultura do Vale do São Francisco, que atende ao mercado externo. Na estatística de 2013, Pernambuco detém seis unidades certificadas.

Na condição de terceiro maior PIB, tanto em 2008 como em 2013, o Ceará possuía sete unidades de negócio certificadas ( $8,75 \%$ da região), destacando-se a empresa Vicunha Nordeste S/A., do setor têxtil, com três unidades certificadas. Dessa forma, os três Estados somavam $82,5 \%$ dos certificados ISO 14001 no Nordeste em 2008. Para 2013, o quantitativo de empresas certificadas diminuiu, mas os três Estados continuaram abrigando 77\% dos certificados ISO 14001 na região Nordeste.

As demais unidades federativas possuem empresas certificadas, exceto Maranhão e Sergipe. Apesar de o Estado do Rio Grande do Norte desenvolver atividades de extração de petróleo, sal e carcinicultura, continua com apenas duas unidades de negócio certificadas. Portanto, a realidade nordestina evidencia que a busca pela certificação ambiental é predominantemente proveniente de empresas que se instalaram em áreas concebidas pelo poder público para serem centros de excelência econômica voltadas para exportação, a exemplo dos complexos industriais. 


\section{Região Centro-Oeste}

De fato, a ocupação e a exploração da região Centro-Oeste ganharam impulso com a transferência da capital do país para Brasília (MONTEIRO, 1981), a partir da qual todos os Estados vêm estabelecendo incentivos para instalação de empresas nas últimas décadas. No entanto, Distrito Federal e Goiás despontam na lista dos dez maiores PIBs no ano de 2010, ocupando o oitavo e o nono lugares, respectivamente, comprovando o peso significativo que desempenham na economia nacional. Associando ao IDH de cada um, observa-se a supremacia do Distrito Federal, tanto a nível regional como nacional. Os demais se colocam entre os dez melhores IDHs. Contudo, ao analisar o número de certificados ISO 14001 na região, nota-se uma participação discreta se comparada às demais.

A análise do gráfico permite identificar a ausência de certificados no Estado do Mato Grosso do Sul (no ano de 2008) e em Mato Grosso (no ano de 2013) (Figura 5).

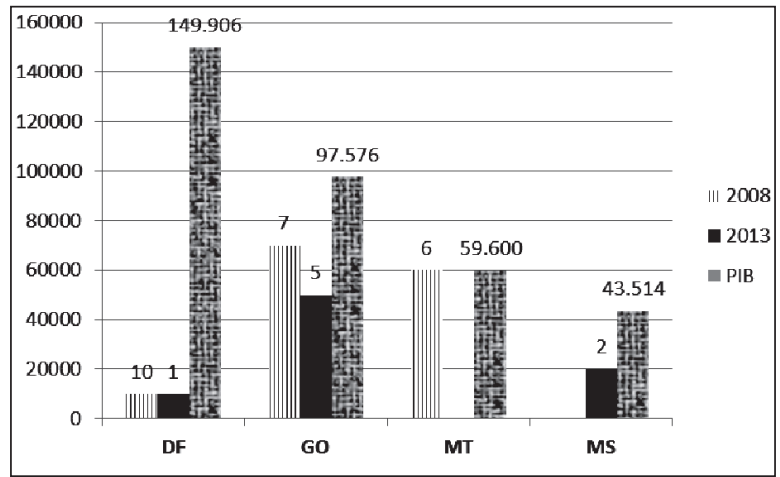

FIGURA 5 - Quantidade de certificados ISO 14001 e valor do PIB (em milhões de reais) na região Centro-Oeste nos anos de 2008 e 2013.

FONTE: INMETRO.

Org.: Do Autor.

O Estado de Goiás (segundo em número de certificações em 2008 e primeiro em 2013) tem sete unidades de negócio (participação regional de aproximadamente $30,5 \%$ ), sendo o nono Estado mais rico da federação e o segundo da região, apresentando uma lista de empresas diversificadas quanto aos setores produtivos: empresa Bunge Alimentos (duas unidades certificadas); Copebras
Ltda., do setor de fertilizantes (duas unidades certificadas), além da Cia. Thermas do Rio Quente, por ser uma das três empresas certificadas pela ISO 14001 no ramo de hotelaria do país, o que possivelmente mostra a deficiência desse setor, mas potencial absorvedor das certificações ambientais, por ser o Brasil um país turístico.

Por fim, o Distrito Federal abrigava o maior número de certificações (dez unidades de negócio) em 2008, perfazendo um total de aproximadamente 43,5\% na região, sendo a Eletronorte detentora da metade dessas certificações. No entanto, há de se considerar que, apesar de ter o melhor desempenho regional, respondia com apenas $1,35 \%$ no cenário nacional, considerando estar entre os dez mais ricos da federação e ter o melhor IDH do país, enquanto em 2013 apresenta apenas uma empresa certificada, segundo o INMETRO. Logo, como possíveis causas para o baixo número de certificados na região pode ser apontada a falta de um grande complexo industrial ou o menor número de empresas que atuam no exterior instaladas na região, devido à dificuldade em se constituir como uma zona de exportação de bens e mercadorias.

\section{Região Sul}

A região Sul é a segunda mais rica e suas unidades federativas são as mais bem posicionadas em relação ao IDH. A ISO 14001 torna-se imprescindível ferramenta de gestão, tanto pelo aspecto do gerenciamento ambiental como pelo viés econômico, já que a região abriga empresas multinacionais e nacionais, que mantêm relações comerciais com outros países. A observação do gráfico permite constatar a liderança do Estado do Paraná, por ter 48 unidades de negócios certificadas em 2008, continuando à frente também em 2013, com 29 unidades certificadas (Figura 6).

Analisando a lista das empresas, não há uma empresa que se destaque no número elevado de unidades de negócio e apenas a PK Cables do Brasil Indústria e Comércio Ltda. possui mais de uma unidade certificada no Estado. A variedade de empresas presentes na lista de certificações é coerente ao seu desempenho econômico e social, sendo a quinta maior economia do país em 2010 e o sexto melhor IDH em 2007. 


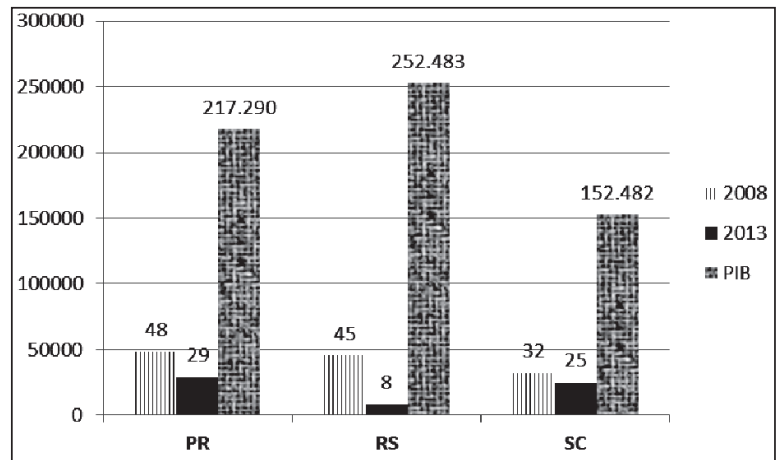

FIGURA 6 - Quantidade de certificados ISO 14001 e valor do PIB (em milhões de reais) na região Sul nos anos de 2008 e 2013. FONTE: INMETRO.

Org.: Do Autor.

O Rio Grande do Sul tem o maior PIB e o melhor IDH da região, mesmo assim ficava abaixo no número de certificações em relação ao Paraná no ano de 2008. Porém, em 2013, apresenta uma diferença de menos vinte e uma unidades certificadas em relação a 2008. O Estado tinha 45 unidades de negócio certificadas, representando 36\% de participação regional. Entre as empresas certificadas, nota-se uma diversidade de setores (indústrias químicas, papel e celulose, transformação de produtos metálicos, alimentícia, vinícolas, etc.). Dentre os diversos setores, vale destacar o setor da indústria de transformação (equipamentos de transportes), indústria de fumo e o da educação. No caso desse último setor, em todo o Brasil existem apenas três unidades de negócio certificadas, das quais duas estão no Rio Grande do Sul (SENAI - Serviço Nacional de Aprendizagem Industrial - e a Unisinos - Universidade do Vale do Rio dos Sinos).

Por fim, Santa Catarina apresentava 32 unidades de negócio certificadas (representando 25,6\% na participação regional), sendo o sétimo Estado mais rico da federação e o segundo melhor IDH. Mesmo com bons indicadores, tem a terceira economia da região e passou a ser o segundo Estado com maior número de certificações em relação aos Estados vizinhos na região. Analisando a lista das unidades de negócio certificadas, chama atenção a grande quantidade de indústrias carboníferas que operam no Estado.

\section{Região Sudeste}

A condição de região economicamente mais rica do Brasil se reflete também no quantitativo de certificações ISO 14001. Em 2008, aproximadamente 65\% das unidades de negócio certificadas no país encontravam-se no Sudeste, com 479 unidades certificadas, chegando em 2013 a 107 unidades.

O gráfico mostra o Espírito Santo com o menor número de certificados, seguindo o posicionamento na lista do PIB e IDH da região. Com um total de onze unidades certificadas, participa com apenas 2,3\% em relação ao total da região, apresentando atualmente apenas uma unidade certificada. Em 2008, destacavam-se a Companhia Vale do Rio do Doce, com duas unidades certificadas (Vila Velha e Vitória), além de empresas nas indústrias de bens de capital, petróleo e química.

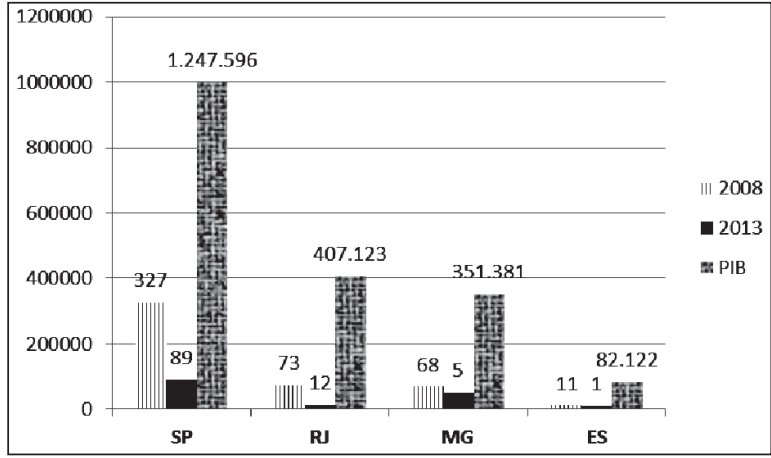

FIGURA 7 - Quantidade de certificados ISO 14001 e valor do PIB (em milhões de reais) na região Sudeste nos anos de 2008 e 2013. FONTE: INMETRO.

Org.: Do Autor.

Minas Gerais totalizava 68 certificações, equivalendo a uma participação regional de $14,2 \%$ e de $9,2 \%$ no total do país. Atualmente, são apenas cinco unidades certificadas. Nacionalmente, destaca-se pelo terceiro maior PIB e o nono melhor IDH. A sua posição economicamente favorável reflete-se no número de certificações, que tem uma lista composta por empresas de setores diversos: mineração, indústria química, indústria extrativa, telefonia, energia e alimentícia. O Estado do Rio de Janeiro caracterizava-se como o segundo no número de certificados (73 unidades de negócio, aproximadamente 
$15,3 \%$ na participação regional e $9,8 \%$ na participação nacional). O Estado é o segundo também no ranking brasileiro de certificações, sendo o segundo maior PIB e o quinto IDH entre os Estados brasileiros. Em 2013, totaliza apenas doze unidades de negócio. As empresas certificadas são de ramos diferenciados (petróleo, indústria de bens de capital e produção, serviços, etc.). Nos dados de 2008 verifica-se uma particularidade no tocante ao fato de um pequeno grupo de empresas (oito) ter 31 unidades de negócios certificadas, representando quase $43 \%$ das unidades certificadas no Estado. Nota-se ainda a grande presença das empresas do ramo de petróleo e derivados, que se relacionam ao fato de ser o Rio de Janeiro o maior produtor desse recurso no Brasil (participação de $73 \%$ na produção nacional). Por fim, cabe destacar uma tendência verificada em outros Estados quanto à certificação das concessionárias de energia elétrica, representadas pela Light Serviços em Eletricidade S/A.

Por fim, os dados evidenciam um domínio absoluto de São Paulo sobre os demais Estados, pois detinha 327 certificados ISO 14001 em 2008, encabeçando a lista regional (aproximadamente $68,3 \%$ das certificações) e nacional (cerca de 44\% das certificações). Em 2013, são 89 unidades certificadas. Tal desempenho pode estar associado aos indicadores socioeconômicos (Estado mais rico e terceiro melhor IDH do país), abrigando o maior parque industrial do país, além da diversificação dos setores produtivos, associado à grande presença de empresas de médio e grande porte, inclusive sedes das maiores multinacionais.

\section{Certificação Ambiental no Brasil por Setores de Atividades}

O estudo das certificações por setores permite reforçar a análise da distribuição destes certificados pelo território nacional e entender melhor que tipo, qual o porte e onde é maior a busca por esse instrumento de gestão. Sendo assim, o INMETRO também disponibiliza em seu banco de dados o quantitativo das empresas certificadas por setores de atividade, classificadas em trinta e um setores. Verifica-se que, do ponto de vista quantitativo, os setores predominantes são as Indústrias de Transformação (o grupo mais representativo é o das empresas dos ramos de Metais de Base e Produtos Metálicos; seguido do grupo das empresas dos ramos de Química de Base, Produtos Químicos, e fibras sintéticas e artificiais), que juntos totalizam 228 certificações, equivalendo a quase $28 \%$ do total das certificações por setores. Esse quantitativo abriga as empresas de mineração e estas, pela natureza das suas atividades, tendem a buscar maiores cuidados com o meio ambiente, consequência das exigências das grandes empresas e do mercado consumidor (Estados Unidos, Japão e países da União Europeia), tornando-se um instrumento quase que obrigatório para esse setor, a fim de se manter competitivo perante o mercado internacional.

Merecem destaque alguns setores que aparentemente causariam "estranheza" em obter a certificação, a exemplo de Educação e Hotéis/Restaurantes. As certificações da educação referem-se à ABASE - Colégio Cristo Rei (ensino fundamental a médio/cursinho) em Marília-SP, SENAI de Estância Velha e a Unisinos em São Leopoldo (ambos no Rio Grande do Sul). No tocante ao setor de Hotéis e Restaurantes, as certificações estão na Pousada Zé Maria (Fernando de Noronha-PE), Cia. Thermas do Rio Quente (Rio Quente-GO) e a Sodexo do Brasil Comercial Ltda. (Limeira-SP). Nota-se a ausência de certificações em alguns setores, como: Administração Pública e Defesa; Seguridade Social Oficial, Pesca, Serviço Doméstico e Organizações e Entidades Estrangeiras.

\section{Considerações finais}

A presença de um SGA no ambiente empresarial conscientiza a empresa de que sua operacionalização e consequente êxito tornam-se um requisito fundamental na sua sobrevivência, enquanto instituição que almeja a conquista de novos mercados e a sustentabilidade econômica. O sucesso no alcance desses objetivos está diretamente relacionado à influência exercida por fatores internos e externos, que agem de modo diferenciado entre os lugares, o que consequentemente se reflete em uma distribuição desigual das certificações 14001 no espaço geográfico.

No entanto, a realidade permite também considerar algumas críticas no tocante à certificação ambiental 
ISO 14001: tem significado uma conferência de padrões considerada pouco seletiva, por ter como referência para certificação o desempenho ambiental com um mínimo de conformidades ambientais atendidas e não disponibiliza meios que possibilitem diferenciar graus de performance ambiental, ou mesmo uma escala de indicação. Outra constatação é que mesmo com a norma ISO 14001 declarando a sua aplicação a organizações de qualquer porte, o levantamento realizado possibilitou constatar que a maior parte das empresas certificadas no Brasil é de médio ou grande porte. Logo, evidencia-se na realidade brasileira a dificuldade por parte das pequenas empresas em obter o certificado do sistema de gestão ambiental.

A análise dos dados da certificação nos induz a afirmar que a maior parte dessas certificações em nível mundial está concentrada nos países desenvolvidos, sede das matrizes das grandes empresas e, por conseguinte, possuem maior poder para inserção dessa ferramenta de gestão. Enquanto isso, a baixa participação em algumas áreas, a exemplo do continente africano, traduz a deficiência econômica dos seus países e a consequente falta de atrativos para instalação das empresas estrangeiras em seu território.

$\mathrm{Na}$ realidade brasileira, a relação (número de certificações, PIB e IDH por unidade da federação) não se mostrou tão evidente, tendo sido constatadas unidades da federação com PIB e IDH inferiores, mas com maior quantidade de certificados em relação a alguns Estados mais bem posicionados socioeconomicamente, fato decorrente da existência complexos industriais, proximidade com fontes de matérias-primas abundantes, áreas de exportação e áreas concebidas pelo poder público (por meio de incentivos fiscais) para instalação de empresas. Mesmo assim, a maior parte das certificações da norma ISO 14001 encontra-se nos Estados de maior PIB (São Paulo, Rio de Janeiro e Minas Gerais), caracterizando uma forte concentração na região Sudeste.

Quanto às áreas que concentram as empresas certificadas, evidencia-se, em alguns Estados (Amazonas e Bahia, por exemplo), que a adesão à certificação ambiental é predominantemente proveniente de empresas instaladas em áreas concebidas pelo poder público para se tornarem centros de excelência econômica voltados para exportação. O predomínio das empresas controladas por grupos estrangeiros (com algumas exceções de empresas de capital nacional) tem como justificativa as relações comerciais externas e o padrão de qualidade exigido internacionalmente, demonstrando o caráter estratégico e mercadológico da ISO 14001. Ou seja, os empreendimentos enquadrados nos setores de grande impacto ambiental (mineração, siderurgia, papel e celulose, etc.) buscam a certificação ambiental objetivando preservar sua imagem perante o mercado e garantir as relações com fornecedores e clientes certificados, que exigem o mesmo das empresas parceiras. Por outro lado, por não estarem sujeitas a tais pressões ou em intensidade bem menor, as pequenas empresas não despertam interesse em aderir à certificação ambiental. Portanto, o território brasileiro possui regras que estão fora dos seus limites.

Logo, nem sempre a certificação ambiental tem relação com a realidade local, sendo uma exigência de fatores externos, como a continuidade em se relacionar com clientes e fornecedores que detêm a certificação ambiental, portanto, algo de fora para dentro, agindo na realidade local.

Assim, constata-se a importância crescente da gestão ambiental no interior das empresas, como também na configuração do espaço geográfico no qual se insere, necessitando desvendar de que forma a ação da sociedade através desse sistema vem interferindo de forma desigual no espaço. Constituindo-se em agente produtor de novos espaços, a certificação ISO 14001 torna-se mais um instrumento de gestão ambiental a alterar a dinâmica social e econômica dos locais onde se faz presente, pois induz à criação de uma série de mecanismos que necessitam, ou melhor, são obrigados a envolver e inserir a população local, poder público, ONGs, etc. A transformação também é verificada na procura por serviços (controle e conservação ambiental), até então pouco requisitados ou inexistentes, para a efetiva operacionalização do Sistema de Gestão Ambiental (SGA), transformando a realidade do território de influência da empresa. 


\section{Referências}

ABNT - Associação Brasileira de Normas Técnicas. NBR ISO 14001 - Sistema de gestão ambiental: especificação e diretrizes para uso. Rio de Janeiro: ABNT, 2004.

CALLENBACH, E. et al. Gerenciamento ecológico - Eco-Management - Guia do Instituto Elmwood de Auditoria Ecológica e Negócios Sustentáveis. São Paulo: Cultrix, 1993.

DIAS, Reinaldo. Gestão Ambiental: responsabilidade social e sustentabilidade. São Paulo: Atlas, 2011.

DONAIRE, D. Gestão ambiental na empresa. São Paulo: Atlas, 1995.

GUTIERRES, H. E. P. Geografia, meio ambiente e ISO 14000. 2008. Monografia (Bacharelado em Geografia) - Universidade Federal da Paraíba, João Pessoa, 2008.

. A efetividade da gestão ambiental nas empresas de mineração no Estado da Paraíba na ótica das comunidades. 2011. Dissertação (Mestrado em Geografia) - Universidade Federal da Paraíba, João Pessoa, 2011.

IBGE - Instituto Brasileiro de Geografia e Estatística. Dados das unidades da Federação. Disponível em: $<$ http://www.ibge. gov.br/estadosat/index.php>.
INMETRO - Instituto Nacional de Metrologia, Normalização e Qualidade Industrial. Gestão ISO 14001. Disponível em: $<$ http://www.inmetro.gov.br/gestao14001>.

ISO - International Organization for Standardization. Relatório Anual ISO 14001 dos anos de 1999, 2005 e 2011. Disponível em: $<$ http://www.iso.org>.

MONTEIRO, C. A. de F. A questão ambiental no Brasil (19601980). São Paulo: Edusp, 1981.

TEODORO, M. E. Estudo sobre o processo de inserção da variável ambiental na grande indústria: A ISO 14000. 2002. Dissertação (Mestrado em Geografia) - USP, São Paulo, 2002.

VITERBO JÚNIOR, Ê. Sistema integrado de gestão ambiental: como implementar a ISO 14000 a partir da ISO 9000, dentro de um ambiente de CQT. São Paulo: Aquariana, 1998.

XAVIER DA SILVA, J. Geografia e meio ambiente no Brasil. In: CHRISTOFOLETTI, A.; BECKER, B. K.; DAVIDOVICH, F. R.; GEIGER, P. P. (Ed.). A pesquisa ambiental no Brasil: uma visão crítica. Rio de Janeiro: Hucitec, 1995.

Recebido em 23 de outubro de 2012. Aceito em 18 de junho de 2013. Publicado em junho de 2013. 